\begin{tabular}{ccc}
\hline International Journal of Engineering \& Technology, $7(4.36)(2018) 432-435$ \\
SPC & Website w ww. sciencepubco.com/index.php/IJET \\
Research paper & Technology \\
\hline
\end{tabular}

\title{
Tool Life and Surface Roughness of A390 Aluminum Alloy in Milling Process Under Dry and Cryogenic Conditions
}

\author{
K.Othman, J.A.Ghani*, J.Afifah, H.A.Rahman, C.H.Haron, N.S.Amin \\ ${ }^{1}$ Centre for Engineering Materials and Smart Manufacturing, Faculty of Engineering and Built Environment, Universiti Kebangsaan \\ Malaysia, 43600 Bangi, Selangor, Malaysia \\ *Corresponding author E-mail: jaharahaghani@ukm.edu.my
}

\begin{abstract}
Aluminum alloy is a lightweight material with high strength-to-weight ratio, low thermal expansion, excellent castability and is applied for heavy wear applications. Recent trends in machining research aimed for improving process and product performance by understand the effect of different cooling/lubrication techniques on machining execution. The milling of A390 Al-Si alloy under dry and cryogenic conditions was investigated and liquid nitrogen $\left(\mathrm{LN}_{2}\right)$ was used as the cryogenic media. The experimental trial were performance with cutting speeds at $250-350 \mathrm{~m} / \mathrm{min}$, feed rates at $0.02-0.04 \mathrm{~mm} /$ tooth, radial depth of cut at $12.5-25 \mathrm{~mm}$, and the axial depth of cut was kept constant at $0.3 \mathrm{~mm}$ using a coated carbide cutting insert. The results outcomes indicate, an application of cryogenic machining had improved the surface roughness, and there was higher tool life as compared to dry cutting condition. The utilization of cryogenic cooling technique had increased the tool life more than $50 \%$ and improved the surface roughness more than $40 \%$ as compared with dry condition. It is suggested to the machining industry to consider the application of LN2 as the cryogenic media to have better machinability in machining A390 Al-Si alloy.
\end{abstract}

Keywords: Dry and cryogenic condition; A390 Al-Si Alloy.

\section{Introduction}

A390 is one of the hypereutectic Al-Si alloy that has strongly recommended material for a certain types of automotive engine components because of better wear resistance and good thermal stability [1]. Excellent properties of A390 Al-Si alloy such as high wear resistance, good corrosion resistance, good mechanical, good physical properties and high thermal conductivity, are suitable for automobile application. These properties are suitable for lightweight components for example engine blocks, cylinder heads, cylinder liners and wheel in the production of fuel-efficient vehicles [2-4].

Cryogenic machining utilizing fluid nitrogen (LN2) as the coolant, has been increment later for most recent two decades, and it keeps draw incredible consideration from the researcher and present day modern industries application. Machining is a metal cutting process to archive the final dimension target of the part's fabrication in order to full fill the parts functional required.

Recently many researchers have demonstrated that cryogenic cooling do not only just keep up on the machinability improvement, also needed to archive the dimensional target and geometrical precision required. Subsequently, cryogenic cooling application also possible to enhance the surface integrity criteria, for instance improve surface finish, increase micro hardness, production of nano-grains. Furthermore, enhancement of wear and corrosion resistance, inducing compressive residual stresses in machined surface layers, thus extending the fatigue life of the machining parts [5].

In this paper the surface roughness and tool life will be examined in the milling process of A390 Al-Si alloy by using cryogenic cooling to assess the surface quality and acceptable cutting time.
The evolution of results obtained of cryogenic and dry machining application have been made and compared.

\section{Materials and Method}

\subsection{Machining Set-up}

The machining experiments in both cutting conditions were conducted on a CNC milling machine (Spinner VC 450, Germany). This vertical milling machine has capability of achieving a maximum speed of 15,000 RPM. In utilized of cryogenic cooling, the gas nitrogen $\left(\mathrm{LN}_{2}\right)$ has been delivered into the machining area using a nozzle at approximately $45^{\circ}$ during the cutting process, as shown in Fig. 1. The workpiece material used for this experiment was A390 Al-Si alloy with dimensions of 125 x 50 × $50 \mathrm{~mm}$ and hardness of $140 \mathrm{BHN}$. In order to ensure an accurate measurement of the surface roughness and cutting time the original skin layer of the workpiece material need to remove due to difference of hardness at skin layer and inner workpiece. Table 1 shows the chemical element of the workpiece material used for this experiment. A Sumitomo face milling cutter diameter $50 \mathrm{~mm}$ with two cutting inserts was used to perform the experiments. The machining parameters and DLC coated cutting insert specifications were shown in Table 2. Table 3 shows the experimental runs conducted in this study. Fig. 2 shows the diamond like carbon (DLC) coated cutting insert dimensions. 


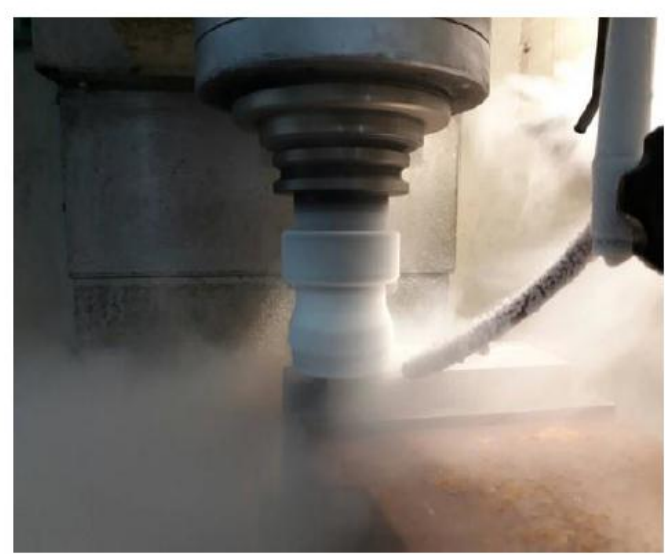

Fig. 1. Experimental set up

Table 1: Chemical elements of A390 Al-Si alloy [8]

\begin{tabular}{lcllccc}
\hline Elements & $\mathrm{Si}$ & $\mathrm{Cu}$ & $\mathrm{Mg}$ & $\mathrm{Fe}$ & $\mathrm{Ti}$ & $\mathrm{P}$ \\
\hline$\%$ wt. & 16.64 & 4.36 & 0.55 & 0.25 & 0.02 & 0.008 \\
\hline
\end{tabular}

Table 2: Exp. parameters and DLC coated cutting insert specification

\begin{tabular}{ll}
\hline Items & Value \\
\hline Cutting speed $(V c)$ & $250,350 \mathrm{~m} / \mathrm{min}$ \\
Feed rate $(F z)$ & $004,0.02 \mathrm{~mm} /$ tooth \\
Axial depth of cut $(a p)$ & $0.3 \mathrm{~mm}$ \\
Radial depth of cut $(a e)$ & $12.5,25 \mathrm{~mm}$ \\
Nose radius $(\mathrm{R})$ & $0.2 \mathrm{~mm}$ \\
Thickness insert & $3.58 \mathrm{~mm}$ \\
Rake angle & $25^{\circ}$ \\
Relief angle & $11^{\circ}$ \\
Rake length & $12 \mathrm{~mm}$ \\
Wide length & $7 \mathrm{~mm}$ \\
\hline
\end{tabular}

\begin{tabular}{lllll}
\multicolumn{5}{c}{ Table 3: Experiment runs } \\
\hline $\begin{array}{l}\text { Experiment } \\
\text { No. }\end{array}$ & $\begin{array}{l}\text { Cuttng } \\
\text { speed, } V c \\
(\mathrm{~m} / \mathrm{min})\end{array}$ & $\begin{array}{l}\text { Feed rate, } f \\
(\mathrm{~mm} / \text { tooth })\end{array}$ & $\begin{array}{l}\text { Radial } \\
\text { depth of } \\
\text { cut, } \text { ar } \\
(\mathrm{mm})\end{array}$ & $\begin{array}{l}\text { Axial depth } \\
\text { of cut, } a p \\
(\mathrm{~mm})\end{array}$ \\
\hline 1 & 250 & 0.02 & 12.5 & 0.3 \\
2 & 250 & 0.02 & 25 & 0.3 \\
3 & 250 & 0.04 & 25 & 0.3 \\
4 & 350 & 0.02 & 12.5 & 0.3 \\
5 & 350 & 0.02 & 25 & 0.3 \\
6 & 350 & 0.04 & 12.5 & 0.3 \\
7 & 350 & 0.04 & 25 & 0.3 \\
8 & 250 & 0.04 & 12.5 & 0.3 \\
\hline
\end{tabular}

\subsection{Measurement of Surface Roughness and Tool Wear}

Surface roughness (Ra) was measured by using a Mitutoyo roughness tester (model SJ-310). The surface roughness measurement recorded at the starting of the machining process with the goal to overcome the effect of tool wear. The measurements were carried out three times of each machine surface, and the average value were calculated. The tool wear measurements on the flank face were taken for each run using Olympus SZ61 stereo measuring microscope.
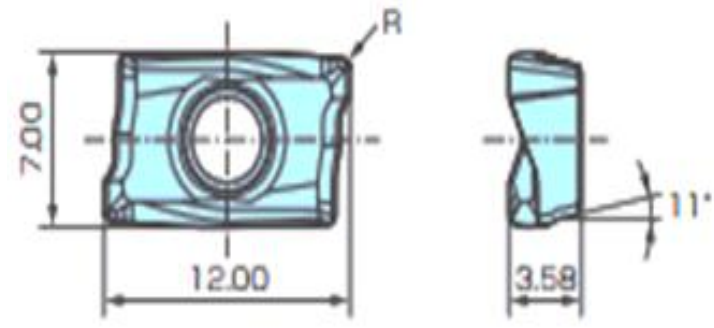

Fig. 2. DLC coated cutting insert dimension

\section{Experimental Results and Analysis}

\subsection{Analysis of Surface Roughness}

Average value of surface roughness ( $\mathrm{Ra}$ ) on the machining surface was measured under dry and cryogenic cutting condition. Fig. 3 shows the average of surface roughness results for each experimentas.

\section{$\rightarrow$ Dry $\rightarrow$ Cryogenic}

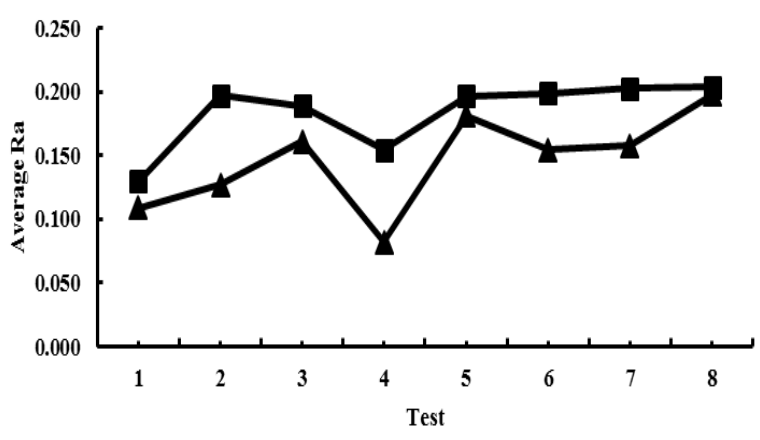

Fig. 3. Average of Ra for all test in dry and cryogenic machining

From the graph, it indicates that average surface roughness from cryogenic machining have the lower surface roughness than that of dry machining. Similar results also been archived by Jerold and Kumar [6] during machining of AISI 105 steel. It was found that the surface finish of the finished part under cryogenic condition is improved to an appreciable amount in comparison with the dry and wet machining condition. The fluctuation on the Ra readings during machining may occur due to chips sticking on the tool rake face. According to Musfirah et al. [7], this scenario could enhance the levels of friction and residual stress at the tool and workpiece interface, resulting in a worse surface roughness. In overall, the experimental test results have shown that cryogenic machining can enhance the Ra by up to a maximum of $47 \%$.

A past research done by Dimas et al. [9] had mentioned that, for A390 Al-Si alloy, the addition of refiner phosphorous results in enhanced surface finish as compared to the parent alloys. This clear is seen from the finer surface roughness $(\mathrm{Ra})$ values archive under similar machining conditions. Moreover, the surface finish of alloys increases with increase in the depth of cut but reduce with increase in the speed. [9]. Dimple structures were fabricated on the A390 Al-Si alloy surface by using turning process in dry condition, as a results $\mathrm{Ra}$ of about $3 \mu \mathrm{m}$ was achieved which is acceptable in its particular application [10]. Optimization study performed by Othman et [11] found that the minimum value of surface roughness of $0.24 \mu \mathrm{m}$ can be achieved with a feed rate approximately at a low level $(0.03 \mathrm{~mm} /$ tooth $)$, depth of cut of 0.29 $\mathrm{mm}$ and high cutting speed of $1490 \mathrm{~m} / \mathrm{min}$ when machining A390 in dry condition.

In this study, however, it was found that under cryogenic condition in a conventional range of cutting speed for Aluminum Alloy, the $\mathrm{Ra}$ was significantly reduced, which agreed with previous findings without changing the A390 compositions.

\subsection{Tool Wear Analysis}

Fig. 4. Illustrates the development of tool wear for different parameter tests in dry and cryogenic machining. According to the test results, under cryogenic cutting conditions resulted in higher tool wear rate than under dry cutting conditions. 


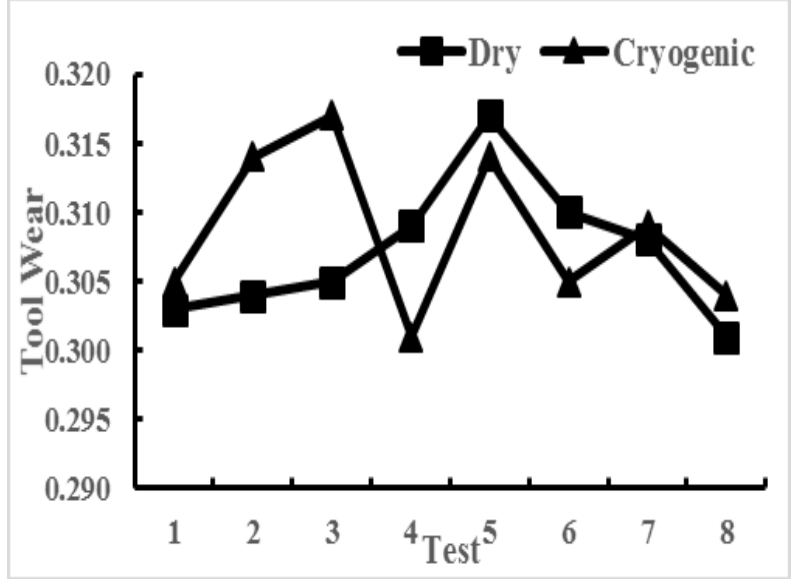

Fig. 4. Measured tool wear in dry and cryogenic milling of A390 Al-Si alloy

The exceedingly low temperatures due to the utilization of fluid nitrogen as a cooling method might cause to brittleness of the tool material, although cryogenic application could decrease the heat generation in cutting area during the machining process [12]. Furthermore, the thermal conductivity will significantly reduce because of the substantial decrease in cutting temperature due to cryogenic application [13]. This circumstance could delay the eliminating of heat conductive at the machining area [14]. Furthermore, due to the interrupted cutting process during the milling process might cause to occurring of the thermal shock at the tool edge. This phenomenon occurs because the tool is exposed under the extreme cold temperature during the application of fluid nitrogen, and immediately warmed up due to evacuation of the chip Subsequently, the drastic temperature changing can lead the tool to shrink and expand repeatedly. Furthermore, this resulted fatigue in the tool as well as has intension to breaks [12]. A significant enhancement in tool life was archive under cryogenic application as compared to dry cutting condition for all the experiments test as shown in figure 5 .

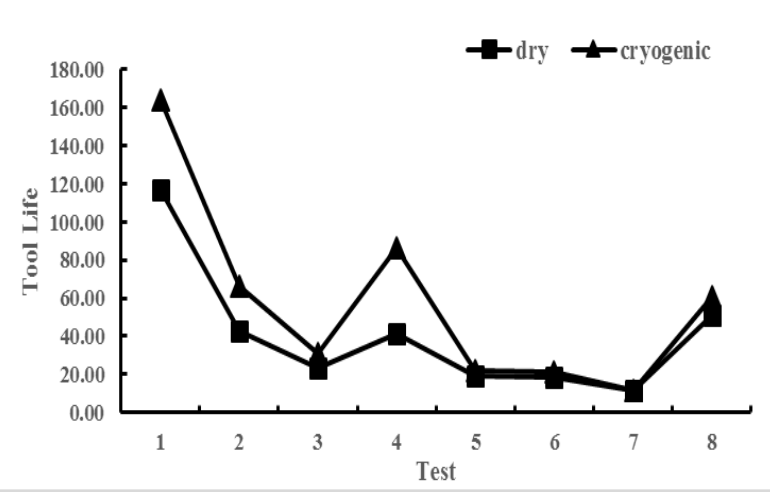

Fig. 5. Measured tool life during dry and cryogenic milling of A390 aluminum alloy

Liu and Chou [15] investigated dry cutting process of hypereutectic silicon-aluminum alloys using the vortex-tube (VT) cooling. The results revealed that VT cooling has the potential to decrease the wear rate in machining of A390 Al-Si alloy, but it depends on the selection of cutting parameter used, the outlet temperature to be considered more critical rather than the flow rate, and decreasing of tool temperature by VT cooling has shown no immediate correlation with reduction of tool wear.

Previous findings also stated that wear mechanism occur during machining process of high silicon aluminum alloys can be categorized as abrasion wear because of cutting tool scratching and crushed with primary Silicon particles [16] adhesion/abrasion wear instigated micro-chipping at the cutting edge area because of periodic removals of the built-up workpiece material at the cutting tool rake surface $[17,18]$. The size of Si particle will also affect the wear mechanism in machining of A390 Al-Si alloy, as stated by Wada [19]. According to him, the size of Si particle include in A390 Al-Si alloy mass is about $17 \%$, it will have a major effect on the tool wear and it was possible to decrease the tool wear by reduce the size of Si particle.

Factors affecting the surface roughness and tool life in cryogenic cooling using LN2 was studied by Badroush et al. [20], the study revealed that the feed rate and cutting speed were highly influenced elements that affecting the tool life, and the interaction of feed rate and depth of cut were significant influence to the surface finish. In cryogenic application of using LN2 has several advantages such as to reduce the temperature generated in the cutting area, and to reduce friction between the chip and the tool. Studied done by Natasha et al. [21] from estimation of coefficient of friction show that use of LN2 during turning process can help the friction decrease up to $73 \%$. It is wanted to obtain the litter estimation value of coefficient of friction, since it demonstrates that the shear edge is bigger. Larger shear angle resulted in littler shear plane area; that provides advantages of small cutting force energy required to shear off the chips and reduce cutting temperature being created during the cutting process.

\section{Conclusions}

The comprehensive study between cryogenic and dry machining in milling of A390 Aluminum Alloy in the context of effectiveness is presented and discussed using of face milling cutter for the machining test. Surface roughness, tool wear and tool life under cryogenic and dry machining were evaluated and analyzed. In view of the experimental investigations and insight obtained base on analysis of results, the following concluding can be determined:

- The application of cryogenic cooling technique will improve the efficiency of lubrication action. These resulted in enhancing the tool life, where contrast with dry condition, the application of cryogenic cooling increased the tool life by $52 \%$.

- The utilization of a cryogenic cooling in machining of A390 Aluminum alloy resulted in an improvement of surface roughness since it could be improved to $47 \%$.

\section{Acknowledgements}

The authors want like to thank the Government of Malaysia and Universiti Kebangsaan Malaysia for their money related help under a FRGS/1/2016/TK03/UKM/01/1 and GUP 2017-048 Grants.

\section{References}

[1] Renninger G, Abendroth D, Bolien M (1983), Casting Engine Blocks in GK Al Si $17 \mathrm{Cu} 4 \mathrm{Mg}$. SAE Congress paper 830003,9-15.

[2] Kapranos P, Kirkwood DH, Atkinson HV, Rheinlander JT, Bentzen JJ, Toft PT, Debel CP (2003), Thixoforming of an automotive part in A390 hypereutectic Al-Si alloy. J Mater Process Tech, 135: 271-277

[3] Lasa L, Rodriguez-Ibab JM (2003), Mater Sci Eng A, 363-193.

[4] Shi X., B. Gao, G.F. Tu, S.W. Li, (2010), Effect of Nd on microstructure and wear resistance of hypereutectic Al-20\% Si alloy. $J$. Alloys Compd. 508, 480-485.

[5] Sun Y, Huang B, Puleo DA, Schoop J, Jawahir IS (2016), Improved Surface Integrity from Cryogenic Machining of Ti-6Al-7Nb Alloy for Biomedical Applications. Procedia CIRP 45, 63-66.

[6] Jerold BD, Kumar MP (2011), Experimental investigation of turning AISI 1045 steel using cryogenic carbon dioxide as the cutting fluid. Journal of Manufacturing Processes 13(2): 113-119

[7] Musfirah, AH, Ghani JA, Che Haron CH (2017), Tool wear and surface integrity of Inconel 718 in dry and cryogenic coolant at high cutting speed. Wear 376: 125-133. 
[8] Showa Denko Aluminum Trading K.K. (2016), Measurement result of Chemical Composition of A390 Al-Si alloy.

[9] Dhiman S, Sehgal R, Sharma SK (2005), Studies Of Machining Parameters Of Al Alloy A-390 During Turning. Proceedings of WTC2005, World Tribology Congress III, September 12-16, Washington DC, USA.

[10] Dali MNAM, Ghani JA, Haron CHC Hassan S (2017), Fabrication of dimple structured surface of A390 Al-Si alloy using turning process. Industrial Lubrication and Tribology, 69(3): 348-354. DOI: 10.1108/ILT-09-2016-0199

[11] Othman K, Ghani JA, Ruslan MS, Kassim MS (2018), Surface roughness of hypereutectic Al-Si A390 in high speed milling, Jurnal Tribologi, 16: 42-50

[12] Nalbant M, Yildiz Y (2011), Effect of cryogenic cooling in milling process of AISI 304 stainless steel. Trans. Nonferrous Met. Soc. China, 21(1):72-79.

[13] Shokrani A, DhokiaV, Muñoz-Escalona P, Newman ST (2013), State of the art cryogenic machining and processing. International Journal of Computer Integrated Manufacturing, 26 (7)

[14] Marquardt E, Le J, Radebaugh R (2002), Cryogenic Material Properties Database, Springer, US, (In Cryocoolers 11).

[15] Liu J, Chou YK (2007), On temperatures and tool wear in machining hypereutectic $\mathrm{Al}-\mathrm{Si}$ alloys with vortex-tube cooling. International Journal of Machine Tools \& Manufacture, 47: 635-645

[16] Oles EJ, Inspektor A, Bauer CE (1996), The new diamond-coated carbide cutting tools. Diamond and Related Materials, 5: 617-624.

[17] Uhlmann E, Lachmund U, Brucher M (2000), Wear behavior of HFCVD diamond coated carbide and ceramic tools. Surface \& Coatings Technology, 131: 395-399.

[18] Uhlmann E, Brucher M (2002), Wear behavior of CVD-diamond tools, CIRP Annals - Manufacturing Technology, 51: 49-52.

[19] Wada T (2015), Si Particle Size-Controlled Al-17 Mass\% Si Alloy and Tool Wear in Cutting Al-17 Mass\% Si Alloy by Polycrystalline Diamond Compact Cutting Tool, Applied Mechanics and Materials, 798: 372-376

[20] Badroush N, Che Haron CH, Ghani JA, Azhar MA, Nurul Hayati AH (2018), Performance of Coated Carbide Tools when Turning Inconel Alloy 718 under Cryogenic Condition using RSM. Journal of Mechanical Engineering, 5(3): 73-87

[21] Natasha AR, Ghani JA, Syariff J, Haron CHC, Hadi MA (2014), Comparison of Dry and Cryogenic Machining on Chip Formation and Coefficient of Friction in Turning AISI 4340 Alloy Steel. Applied Mechanics and Materials, 554:7-11 